\title{
Diclofenac-Induced Kidney Damage in Wistar Rats: Involvement of Antioxidant Mechanism
}

\author{
Tijani S. Abiola ${ }^{*}$, Oyindamola C. Adebayo², 0. 0. Babalola ${ }^{3}$ \\ ${ }^{1}$ Department of Biochemistry, Bowen University, Iwo, Nigeria \\ ${ }^{2}$ Department of Development and Regeneration, Katholieke Universiteit, Leuven, Leuven, Belgium \\ ${ }^{3}$ Department of Biochemistry and Molecular Biology, Obafemi Awolowo University, Ile Ife, Nigeria \\ Email: `tijaniabiol@yahoo.com, damola.adebayo@student.kuleuen.be, doctorbablo@yahoo.com
}

How to cite this paper: Abiola, Ti.S., Adebayo, O.C. and Babalola, O.O. (2019) Diclofenac-Induced Kidney Damage in Wistar Rats: Involvement of Antioxidant Mechanism. Journal of Biosciences and Medicines, 7, 44-57.

https://doi.org/10.4236/jbm.2019.712005

Received: October 25, 2019

Accepted: November 28, 2019

Published: December 2, 2019

Copyright ( 2019 by author(s) and Scientific Research Publishing Inc. This work is licensed under the Creative Commons Attribution International License (CC BY 4.0).

http://creativecommons.org/licenses/by/4.0/

(c) (i) Open Access

\begin{abstract}
Kidney damage has been associated with administration diclofenac, a phenylacetic acid derivative belonging to the nonsteroidal anti-inflammatory drugs (NSAIDs), which is commonly used for the treatment of various diseases such as rheumatoid arthritis, ankylosing spondylitis, acute muscle pain conditions and osteoarthritis. This study investigated the exact mechanism of diclofenac in renal toxicity by determining the involvement of oxidative stress in rats. Adult male Wistar rats were divided into two groups of eight rats in each group and orogastrically treated for three days. Group 1 served as the normal control and received normal saline $(0.9 \% \mathrm{w} / \mathrm{v})$ and group 2 received $40 \mathrm{mg} / \mathrm{kg}$ body weight of diclofenac for three days. Administration of diclofenac caused degeneration of the kidney of rats as evidenced by significant elevation in the serum levels of creatinine, urea, albumin, uric acid, protein and electrolytes and the activities of renal-5'-nucleotidase and glucose-6-phosphate-dehydrogenase (G6PDH) compared with control. Furthermore, administration of diclofenac decreased the activities of superoxide dismutase (SOD), catalase, glutathione peroxidase (GPx), and glutathione-S-transferase (GST) and the level of glutathione with concomitant increase in hydrogen peroxide $\left(\mathrm{H}_{2} \mathrm{O}_{2}\right)$ and malondialdehyde (MDA) levels in the kidney of the diclofenac treated groups compared with control. These findings reveal that administration of diclofenac may impair kidney functions through induction of oxidative stress.
\end{abstract}

\section{Keywords}

Orogastrically, Oxidative Stress, Toxicity, Diclofenac, Kidney Damage

\section{Introduction}

The kidney is highly susceptible to chemical damage, compared to other organs, 
partly owing to its unequally high blood flow, and because of its complexity both anatomically and functionally. The kidney regulates various activities in the body such as maintenance of water balance, electrolyte balance acid-base balance, secretion of hormones and hemopoietic function as well as long term regulation of arterial blood pressure via renin-angiotensin mechanism and by regulation of extracellular fluid [1].

Non-Steroidal Anti-Inflammatory Drugs (NSAIDs) are one of the most commonly prescribed drugs for inflammation and pain and their nephrotoxic effects are well known [2] [3]. NSAIDs exert anti-inflammatory, analgesic and antipyretic effects through the suppression of prostaglandin (PG) synthesis, by inhibiting the enzyme cyclooxygenase (COX). Cyclooxygenase exists in two isoforms: COX1 expressed constitutively in the kidney and functions mainly in the control of renal hemodynamic and glomerular filtration rate (GFR) and COX2 which is inducible in most tissues in response to injury or inflammation, but also present at detectable levels in normal adult mammalian kidneys and its functions primarily affect salt and water excretion [4] and is regulated in response to intravascular volume. Obstruction of any or both of these enzymes can therefore have diverse effects on renal function. Prostaglandins control a wide range of renal functions. PGE2 is considered to be primarily a tubular PG and regulates sodium and chloride transport in the loop of Henle and moderates water transport and renal medullary blood flow [4] while PGI2 a vascular PG controls renal vascular tone, GFR and renin release COX-2 stimulates the renin-angiotensin system, while an increased activity of the renin-angiotensin system inhibits COX-2. PGI2 and PGE2 increase potassium secretion primarily by stimulating the secretion of renin and activating the renin-angiotensin-aldosterone system [5].

The kidneys and the gastrointestinal tract are main foci for untoward clinical events associated with the use of NSAIDs [6]. Diclofenac is one of the most widely NSAID used to decrease inflammation and arthritis-associated pain [7] [8]. It is rapidly and completely absorbed after consumption and attaches to albumin in plasma [9]. Its side effects include nephrotoxicity and liver toxicity [10] [11] amongst others. Some serum parameters are used to evaluate organ damage. Increased serum urea and creatinine concentrations are accepted as indicators of kidney damage.

Normally, combinations of biochemical and physiological phenomena play a key role in kidney vulnerability and renal toxicity [12]. Diclofenac toxicity has been associated with oxidative stress but there is paucity of information on the involvement of antioxidant mechanism. This study therefore investigated the detailed mechanisms of action of diclofenac on kidney damage.

\section{Materials and Methods}

\subsection{Chemicals and Reagents}

Glucose-6-phosphate, adenosine monophosphate (AMP), trichloroacetic acid 
(TCA), bovine serum albumin (BSA), Folin-Ciocalteau reagent, methanol, epinephrine, reduced glutathione, Ellman's Reagent [5'-5'-dithiobis-(2-dinitrobenzoic acid), DNTB], sulphosalicylic acid, trichloroacetic acid (TCA), thiobarbituric acid (TBA), reduced glutathione,1-chloro-2, 4-dinitrobenzene were supplied by Sigma-Aldrich ${ }^{\circledast}$ (USA), were purchased from Sigma Aldrich Chemical Co. (St. Louis, MO, USA). Albumin kit, urea kit, creatinine kit and Uric acid kit from Randox Laboratories Limited. Other chemicals and reagents used were of analytical grade.

\subsection{Experimental Animals}

Forty male Wistar strain albino rats (150 - $170 \pm 5 \mathrm{~g})$ were procured from Central Animal House, Faculty of Basic Medical Science, College of Medicine, University of Ibadan, Ibadan, Nigeria. To avoid coprophagy, rats were kept in polyethylene-walled cages in a temperature-controlled room $\left(25^{\circ} \mathrm{C} \pm 2{ }^{\circ} \mathrm{C}\right)$ with 12 $\mathrm{h}$ light and $12 \mathrm{~h}$ dark cycle prior to the experiments and were fed with standard rat's chow (Ladokun Feeds, Nigeria) with fresh water ad libitum. All procedures in this study conformed to the guiding principles for research involving animals as recommended by the Declaration of Helsinki and the Guiding principles in the care and use of animals and as approved by the Research Ethical Committee, Bowen University, Nigeria. The rats were deprived of food for 18 hours but had free access to clean water prior to the commencement of the experiment.

\subsection{Drug}

Diclofenac (Novartis Pharmaceutical Limited, Malaysia) was purchased from the Pharmacy unit of Bowen University Teaching Hospital (BUTH), Iwo, Osun State. The tablets were dissolved in normal saline $(0.9 \% \mathrm{v} / \mathrm{v})$.

\subsection{Experimental Design}

Sixteen adult male Wistar rats weighing (180.5 $\pm 20.0 \mathrm{~g})$ were purchased from the Central Animal House, Faculty of Basic Medical Science, College of Medicine, University of Ibadan, Nigeria. Animals were kept in a temperature-controlled room $\left(25^{\circ} \mathrm{C} \pm 2^{\circ} \mathrm{C}\right)$ with $12 \mathrm{~h}$ light and $12 \mathrm{~h}$ dark cycle. The rats were kept in polypropylene cages under standard laboratory conditions and were fed with standard rat's pellet (Ladokun Feeds, Nigeria) with fresh water adlibitum. They were acclimatized for 14 days. All the animals received humane care according to the criteria outlined in the "Guide for the Care and Use of Laboratory Animals" prepared by the National Academy of Science and published by the National Institute of Health [13]. The experiment was performed according to the guidelines and approval of institutional animal ethics committee.

Rats were divided into two groups of eight rats per groups and treated orally once daily for three days by oral gavage. Rats in group 1 received $1 \mathrm{ml} / \mathrm{kg}$ body weight of normal saline and group 2 received $40 \mathrm{mg} / \mathrm{kg}$ for three days. Twenty four hours after the last dose, all animals were humane sacrificed by cervical dislocation. 


\subsection{Serum Preparation and Post Mitochondrial Fraction Collection}

After sacrifice, blood from each rat was collected separately by cardiac puncture technique using sterilized needles and syringes into clean anticoagulant-free centrifuge tubes. Then, the blood was allowed to coagulate by standing for about 30 minutes, and the serum in each tube was separated by centrifugation at 4000 $\mathrm{g}$ for $10 \mathrm{~min}$ with a table centrifuge. Subsequently, the kidneys of each rat were quickly removed, rinsed in ice-cold $1.15 \% \mathrm{KCl}$. The portions of the kidneys were then homogenized in $0.1 \mathrm{M}$ phosphate buffer $\mathrm{pH} 7.4$ with the aid of potter-Elvehgen homogenizer. The homogenates were then centrifuged at $10,000 \mathrm{~g}$ for $10 \mathrm{~min}$ in a cold centrifuge at $4^{\circ} \mathrm{C}$, and the supernatants (post mitochondrial fractions) were used for the determination of the oxidative stress and antioxidant markers.

\subsection{Serum Biochemistry}

The levels of serum urea, creatinine, albumin and uric acid were estimated by Fawcett and Scott [14] and Henry [15], Tietz [16], Fossati et al. [17] and Glucose-6-phosphate dehydrogenase activity by method of Webster [18] respectively were evaluated spectrophotometrically by an Ultrospec $2000^{\circ}$ spectrophotometer (Pharmacia Biotech, Uppsala, Sweden) in accordance with the methods provided by the diagnostic kits (Randox Laboratories Limited, UK) respectively. Serum electrolytes (sodium, potassium, calcium, chloride, phosphate and bicarbonate ions) were determined by flame photometry.

\subsection{Biochemical Studies}

\subsubsection{Determination of Kidney Renal-5'-Nucleotidase Activity}

The activity of Renal-5'-Nucleotidasecarried out according to the method described by George et al. [19]. Briefly, $0.15 \mathrm{ml}$ of AMP was incubated with $0.1 \mathrm{ml}$ of $5 \mathrm{mM}$ Tris- $\mathrm{KCl}$ ( $\mathrm{pH} 7.6$ ) followed by $0.1 \mathrm{ml}$ of $10 \mathrm{mM} \mathrm{MgCl}_{2}$ and $0.15 \mathrm{ml}$ aliquot kidney homogenate (PMF) at $37^{\circ} \mathrm{C}$ for 20 minutes. The reaction was stopped by addition of $0.5 \mathrm{ml} 10 \%(\mathrm{w} / \mathrm{v})$ trichloroacetic acid and the protein precipitate was removed by centrifugation. $0.5 \mathrm{ml}$ of supernatant was added to $0.5 \mathrm{ml}$ of ammonium molybdate, then $0.8 \mathrm{ml}$ of ferrous sulphate solution. The optical density was measured at $700 \mathrm{~nm}$ after shaking. The kidney Renal-5'-Nucleotidase activity was expressed as $\mu \mathrm{mol} / \mathrm{mg}$ protein.

\subsubsection{Determination of Kidney Superoxide Dismutase (SOD) Activity}

The SOD activity was determined based on the principle of inhibition of autoxidation of epinephrine ( $\mathrm{pH} 10.2)$ at $30^{\circ} \mathrm{C}$ [20]. The assay mixture contained $20 \mu \mathrm{L}$ of the kidney supernatant sample, and $2.5 \mathrm{~mL}$ of carbonate buffer $(0.05 \mathrm{M}, \mathrm{pH}$ 10.2). Then, $0.3 \mathrm{~mL}$ of freshly prepared solution of adrenaline $(0.3 \mathrm{mM})$ was added after equilibration in the spectrophotometer and mixed by inversion. Thereafter, the increase in absorbance was monitored in a spectrophotometer at $480 \mathrm{~nm}$ for $150 \mathrm{~s}$ at $30 \mathrm{~s}$ intervals. The kidney SOD activity was expressed in 
Units/mg of protein.

\subsubsection{Determination of the Activity of Catalase (CAT) in the Kidney}

The activity of catalase was evaluated by monitoring $\mathrm{H}_{2} \mathrm{O}_{2}$ clearance at $240 \mathrm{~nm}$ for $2 \mathrm{~min}$ at $10 \mathrm{~s}$ intervals using a UV-vis spectrophotometer [21]. The reaction assay contained $1800 \mu \mathrm{L}$ of phosphate buffer ( $50 \mathrm{mM}, \mathrm{pH}$ 7.0), $180 \mu \mathrm{L}$ of $\mathrm{H}_{2} \mathrm{O}_{2}$ (300 mM), and $20 \mu \mathrm{L}$ of the kidney supernatant sample. The activity of catalase was expressed as $\mu \mathrm{mol} \mathrm{H}_{2} \mathrm{O}_{2}$ consumed/min/mg protein.

\subsubsection{Determination of the Activity of Kidney Glutathione Peroxidase (GPx) Activity}

The GPx activity was determined using the method of Rotruck et al. [22]. The reaction mixture which contained $500 \mu \mathrm{L}$ sodiumphosphate buffer, $100 \mu \mathrm{L}$ of $10.0 \mathrm{mM}$ sodium azide, $200 \mu \mathrm{L}$ of $4.0 \mathrm{mM} \mathrm{GSH}, 100 \mu \mathrm{L}$ of $2.5 \mathrm{mM} \mathrm{H}_{2} \mathrm{O}_{2}$, and 50 $\mu \mathrm{L}$ kidney sample was made up to $2.0 \mathrm{~mL}$ with distilled water. This was followed by incubation for $3 \mathrm{~min}$ at $37^{\circ} \mathrm{C}$, and termination of the reaction by the addition of $0.5 \mathrm{~mL}$ of $10 \%$ trichloroacetic acid. Subsequently, the mixture was centrifuged and the supernatant obtained was used to evaluate residual level of GSH by the addition of $4.0 \mathrm{~mL}$ of disodium hydrogen phosphate $(0.3 \mathrm{M})$, and $1 \mathrm{~mL}$ of DTNB reagent. The absorbance was then read at $412 \mathrm{~nm}$ in a spectrophotometer and the activity of GPx was expressed as units/mg protein.

\subsubsection{Determination of Glutathione S-Transferase (GST) Activity}

The activity of GST was determined in the kidney of rats using the method of Habig et al. [23]. This assay involves the pre-incubation of a mixture containing $1.7 \mathrm{~mL}$ of $100 \mathrm{mmol} / \mathrm{L}$ of phosphate buffer $(\mathrm{pH} 6.5)$ and $0.1 \mathrm{~mL}$ of $30 \mathrm{mmol} / \mathrm{L}$ of $\mathrm{CDNBat} 37^{\circ} \mathrm{C}$ for $5 \mathrm{~min}$. After the addition of $20 \mu \mathrm{L}$ of the sample, the absorbance of the solution was monitored at a wavelength of $340 \mathrm{~nm}$ in a spectrophotometer for $5 \mathrm{~min}$. Subsequently, GST activity was expressed in units $/ \mathrm{min} / \mathrm{mg}$ protein using an extinction coefficient of $9.6 \mathrm{mM}^{-1} \cdot \mathrm{Cm}^{-1}$.

\subsubsection{Determination of Glutathione (GSH) Level}

The determination of the GSH level was carried out using the method of Jollow et al. [24]. An aliquot of the kidney samples was deproteinized by the addition of an equal volume of sulphosalicylic acid (4\%) and centrifuged at 10,000 g for 15 $\min$ at $4^{\circ} \mathrm{C}$. Thereafter, $50 \mu \mathrm{L}$ of the supernatants obtained was added to DTNB $(10 \mathrm{mM}, 4.5 \mathrm{~mL})$, and the absorbance was read at $412 \mathrm{~nm}$. The values were then expressed in $\mu \mathrm{mol} / \mathrm{mg}$ protein.

2.7.7. The Determination of Malondialdehyde (MDA) Level in the Kidney The level of malondialdehyde (MDA which is a marker of lipid peroxidation (LPO)) was determined using the method of Buege and Aust [25]. Each of the kidney supernatant $(0.4 \mathrm{~mL})$ was mixed with Tris- $\mathrm{KCl}$ buffer $(1.6 \mathrm{~mL})$ containing $0.5 \mathrm{~mL}$ of trichloroacetic acid (30\%). This was followed by the addition of 0.5 $\mathrm{mL}$ of $0.75 \%$ thiobarbituric acid to each of the tubes. The tubes were then incubated at $80^{\circ} \mathrm{C}$ for $45 \mathrm{~min}$ in a water bath, cooled in ice, and centrifuged at $3000 \mathrm{~g}$. 
Subsequently, the absorbance of the clear supernatant in each tube was read in a spectrophotometer against a reference blank at $532 \mathrm{~nm}$. The LPO status was then expressed in $\mu \mathrm{mol} \mathrm{MDA}$ formed/mg protein using a molar extinction coefficient of $1.56 \times 105 \mathrm{~m}^{-1} \cdot \mathrm{cm}^{-1}$.

\subsubsection{Determination of Hydrogen Peroxide $\left(\mathrm{H}_{2} \mathrm{O}_{2}\right)$ Generated in the Kidney}

Kidney hydrogen peroxide $\left(\mathrm{H}_{2} \mathrm{O}_{2}\right)$ generated was determined based on the method of Wolff [26], based on oxidation of ferrous with xylenol orange. The kidney supernatant $(50 \mu \mathrm{L})$ was added to a mixture containing $100 \mu \mathrm{M} / \mathrm{L}$ of xylenol orange, $250 \mu \mathrm{M} / \mathrm{L}$ of ammonium ferrous sulphate, $100 \mathrm{mmol} / \mathrm{L}$ of sorbitol, and $25 \mathrm{mmol} / \mathrm{L}$ of $\mathrm{H}_{2} \mathrm{SO}_{4}$ and vortexed. This was followed by incubation for $30 \mathrm{~min}$ at room temperature. The absorbance was then read spectrophotometrically at $560 \mathrm{~nm}$ and the values were expressed in $\mathrm{nmol} / \mathrm{mg}$ protein.

\subsubsection{Determination of Protein Concentration}

The protein concentration in the kidney of the rats was determined by the method described by Gornall et al. [27] with some modifications. Potassium iodide was added to the reagent in order to prevent precipitation of $\mathrm{Cu}^{2+}$ ions as $\mathrm{cu}$ prousoxide.

\subsection{Histological Assessment of the Kidney}

Representative kidney sections $(5 \mu \mathrm{m})$ from the control and diclofenac-treated rats were fixed in $10 \%$ formalin, and processed for histology using standard procedure [28]. Then, the slides were coded and examined under a light microscope (Olympus CH; Olympus, Tokyo, Japan) by pathologists who were blinded to control and diclofenac groups. Photomicrographs were taken with a Sony DSC-W 30 Cyber-shot (Sony, Tokyo, Japan).

\subsection{Statistical Analysis}

Data obtained were statistically analyses using Graph Pad Prism (Version 7.0), and the data were expressed as Mean \pm Standard error of mean. Statistical significant differences were determined using a one-way analysis of variance (ANOVA), followed by Duncan's multiple comparisons test using Statistical packages for social Scientists version 18.0 (SPSS version 18.0). Value of $p<0.05$ was considered statistical significant.

\section{Results}

\subsection{Diclofenac Induced Kidney Dysfunction}

To examine the integrity of the kidney following administration of diclofenac to rats, the concentrations of biomarkers of renal dysfunction were determined. The effects of diclofenac on $\mathrm{Na}^{+}, \mathrm{K}^{+}, \mathrm{Ca}_{2}^{+}, \mathrm{PO}_{4}^{2-}, \mathrm{HCO}_{3}^{-}, \mathrm{Cl}^{-}$, protein, urea, creatinine, albumin and uric acid levels in the kidneys of rats are shown in Table 1 and Figure 1 respectively. The result indicated that diclofenac administration 
Table 1. Biomarkers of renal dysfunction in rats exposed to diclofenac.

\begin{tabular}{|c|c|c|c|c|c|c|c|}
\hline Parameters & $\mathrm{Na}^{+}(\mathrm{mmol} / \mathrm{L})$ & $\mathrm{K}^{+}(\mathrm{mmol} / \mathrm{L})$ & $\mathrm{Ca}^{2+}(\mathrm{mmol} / \mathrm{L})$ & $\mathrm{Cl}^{-}(\mathrm{mmol} / \mathrm{L})$ & $\mathbf{P O}_{4}^{2-} \quad(\mathrm{mmol} / \mathrm{L})$ & $\mathrm{HCO}_{3}^{-}(\mathrm{mmol} / \mathrm{L})$ & Protein (mg/dl) \\
\hline Control & $18.08 \pm 0.21$ & $3.16 \pm 0.32$ & $6.51 \pm 0.23$ & $14.20 \pm 0.21$ & $4.12 \pm 0.25$ & $2.05 \pm 0.02$ & $5.47 \pm 0.17$ \\
\hline Diclofenac & $42.68 \pm 1.05^{*}$ & $8.12 \pm 0.87^{*}$ & $8.02 \pm 0.13^{*}$ & $26.14 \pm 1.03^{*}$ & $6.57 \pm 0.11^{*}$ & $5.21 \pm 0.26^{*}$ & $7.52 \pm 0.19^{*}$ \\
\hline
\end{tabular}

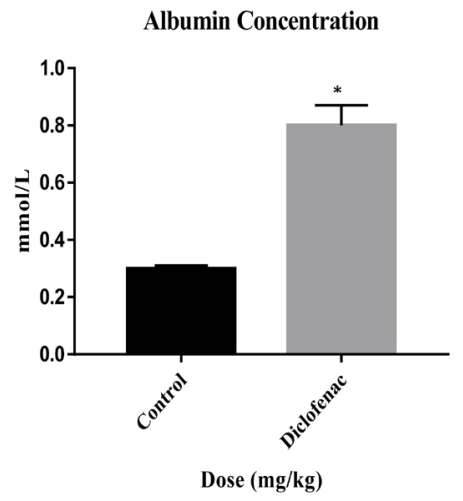

(a)

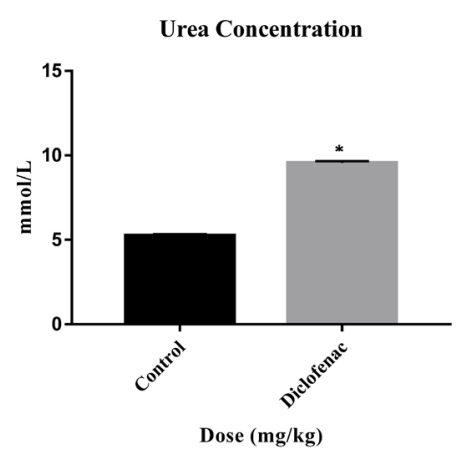

(c)

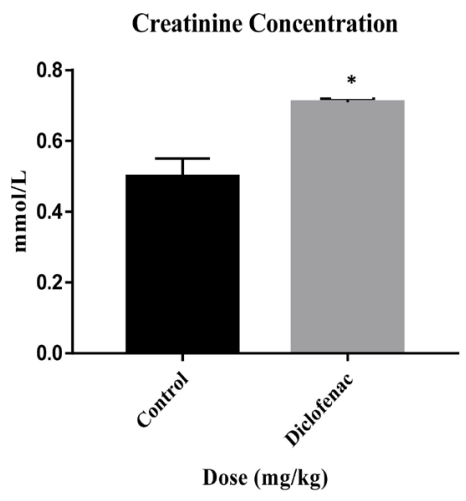

(b)

Uric Acid Concentration

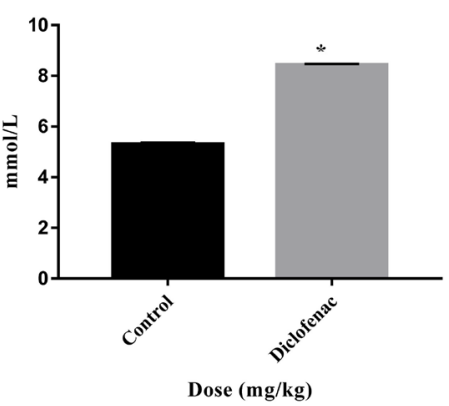

(d)

Figure 1. Concentrations of albumin, creatinine, urea and uric acid of control and diclofenac treated rats. Each bar represents mean \pm standard error of mean. ${ }^{*} \mathrm{p}<0.05$ is significant when compared with the diclofenac group.

to rats caused a significant elevation $(\mathrm{p}<0.05)$ in the concentration of serum albumin, creatinine, urea and uric acid and all the electrolytes levels when compared with the control.

Diclofenac provoked changes in the activities renal-5'-nucleotidase, G6PDH and antioxidant enzymes of kidney following administration of diclofenac to rats for 3 days. Renal-5'-nucleotidase and G6PDH activities in the diclofenac treated rats kidney were significantly elevated compared with control at $\mathrm{p}<0.05$ (Figure 2(a) and Figure 2(b)). The activities of antioxidant enzymes after the treatment of rats with diclofenac are also depicted in Figures 2(c)-(f). There were significant $(\mathrm{p}<0.05)$ decrease in the activities of SOD, CAT GPx and GST; a drug metabolizing enzyme.

The level of GSH is shown in Figure 3(a) following treatment of rats with diclofenac for 3 days. The GSH level was significantly lowered in the kidneys of rats administered with $40 \mathrm{mg} / \mathrm{kg}$ body weight of diclofenac when compared with 


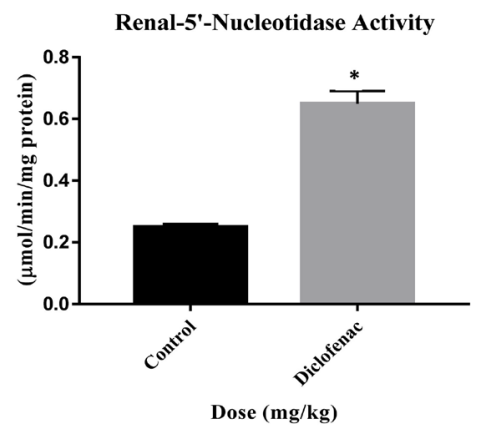

(a)

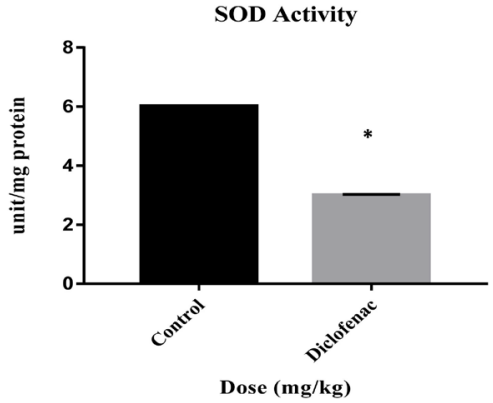

(c)

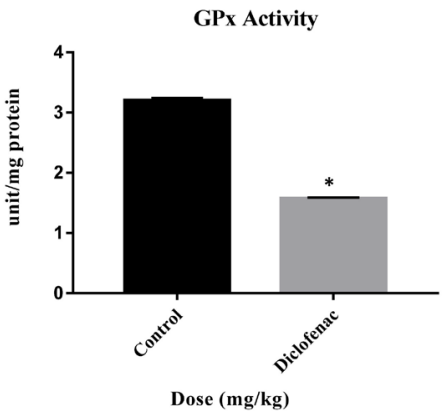

(e)

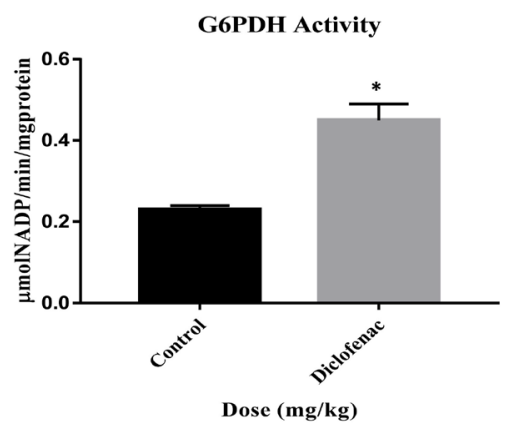

(b)

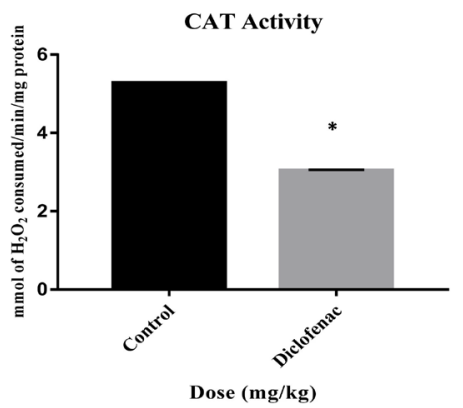

(d)

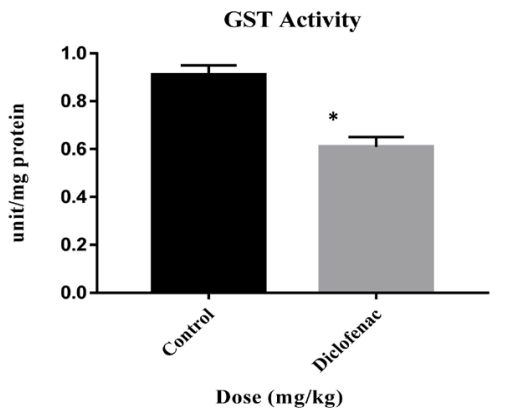

(f)

Figure 2. Activities of renal-5'-nucleotidase, G6PDH, SOD, CAT, GPx and GST of control and diclofenac treated rats. Each bar represents mean \pm standard error of mean. ${ }^{\star} \mathrm{p}<$ 0.05 is significant when compared with the diclofenac group.

the control rats $(\mathrm{p}<0.05)$. In addition, the data on the levels of MDA, an index of lipid peroxidation, and $\mathrm{H}_{2} \mathrm{O}_{2}$ generated following treatment of rats with diclofenac are depicted in Figure 3(b) and Figure 3(c) respectively. The MDA and $\mathrm{H}_{2} \mathrm{O}_{2}$ generated were elevated in the kidneys of rats that received $40 \mathrm{mg} / \mathrm{kg}$ body weight of diclofenac when compared with the control rats $(\mathrm{p}<0.05)$.

\subsection{Histopathological Findings}

The histological examinations of kidney tissues of the control and diclofenac-treated group of rats revealed the kidney section of the control rats was normal (Figure 4(a)). Diclofenac-treated rat (Figure 4(b)), showed congestion of the blood vessels of the renal parenchyma with mononuclear cells filtration and dilation of the renal tubules (black arrow). 


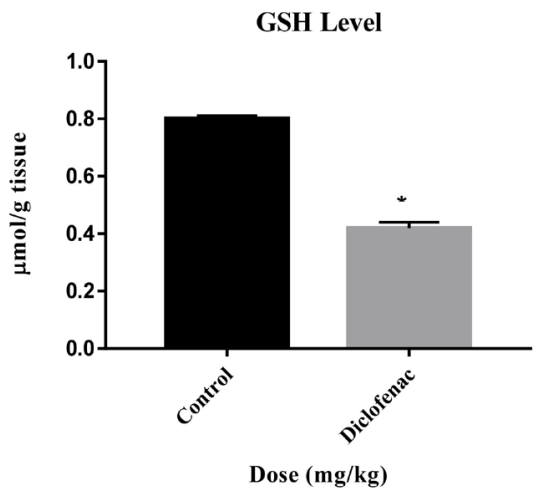

(a)

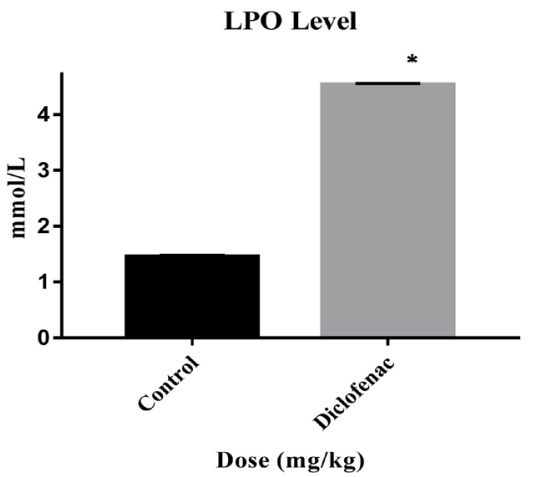

(b)

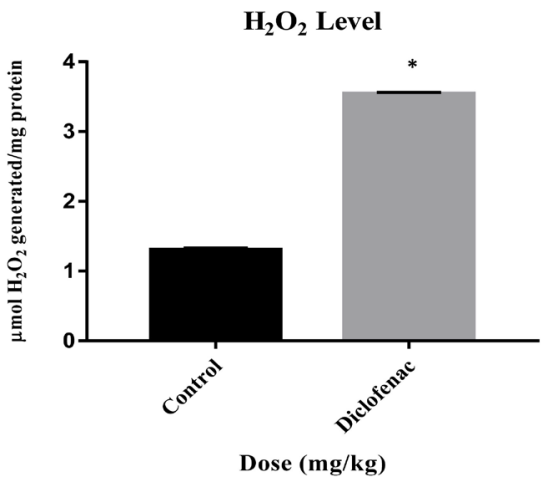

(c)

Figure 3. Levels of reduced glutathione, lipid peroxidation and activity of hydrogen peroxide generated of control and diclofenac treated rats. Each represents mean \pm standard error of mean. ${ }^{*} \mathrm{p}<0.05$ is significant when compared with the piroxicam alone group.

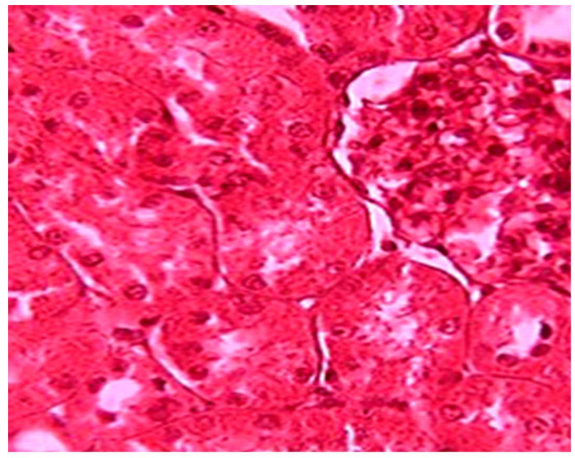

(a)

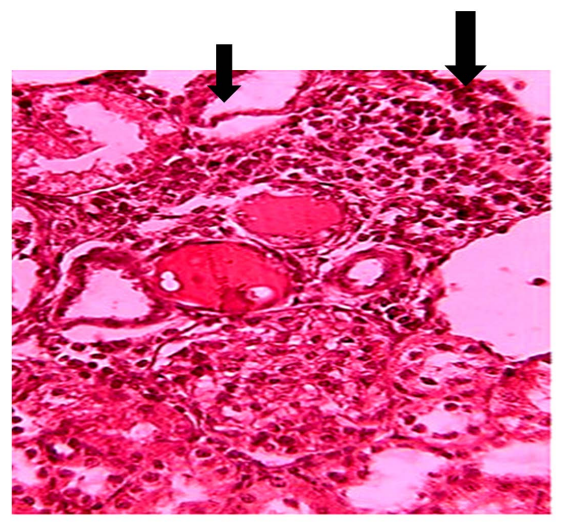

(b)

Figure 4. Effect of diclofenac on renal histopathology of rats. (a) Control rat: show normal renal architecture with healthy glomerulus and kidney tubule arrangement; (b) Diclofenac-treated rat: show inflammation and dilation of kidney tubules. $\times 100$.

\section{Discussion}

Diclofenac, a non-steroidal anti-inflammatory drug, have an undesirable consequence on renal functioning. Diclofenac inhibits renal endogenous prostaglandin production, decreases renal afferent vasodilation, raises afferent resistance; 
all of this causes the glomerular capillary pressure to fall below normal values and decline in Glomeruli Filtration Rate (GFR) [28]. These are displayed as acute renal dysfunction, fluid, and electrolyte disorders and pathologically reveal renal papillary necrosis, interstitial nephritis [28].

Serum creatinine, urea, uric acid and electrolytes levels are the most important clinical parameters for evaluating abnormalities in renal function. Serum investigation of creatinine, urea, uric acid, sodium, potassium was impaired and severe tubular damage was noticed in this study. Creatinine is an anhydride of creatine and is generated by spontaneous and irreversible reaction in skeletal muscle metabolism. Serum creatinine is one of the kidney variables that indicate renal toxicity. Creatinine may be suggestive of kidney-specific functional maladies [29]. An increase in serum creatinine is a biomarker for renal damage. Urea is formed by the liver and considered the main end product of protein catabolism in mammals especially humans. Plasma urea levels can be a dependable indicator of renal function [30]. Uric acid is produced by the breakdown of purines and by direct synthesis from 5-phosphoribosyl pyrophosphate (5-PRPP) and glutamine. Uric acid is excreted in the urine in humans, but in other mammals, uric acid is further metabolized to allantoin before excretion. Another probable explanation for the elevated serum uric acid level in diclofenac treated group may be because uric acid been an electron donor; donates electrons in defence against free radical-generated oxidative damage [31]. This may exacerbate the condition of renal damage resulted from uric acid. The results of these biomarkers in this study are in accordance with the reports of [32] [33] [34]. Diclofenac-induced nephrotoxicity was manifested by elevation in the serum levels of creatinine, urea, and uric acid, and was confirmed through oxidative stress disturbances that have been reported by many workers [11].

In normal conditions, the glomerulus restricts the migration of high molecular weight proteins from blood to nephron lumen by filtration [35]. In some pathological states, however, high molecular weight proteins can be detected in the urine because the selective penetration through glomerulus is not functioning properly [36]. High molecular weight proteins that can reveal kidney damage include albumin which can be used for early diagnosis of changed glomerular filtration and diabetes [32]. In this study, there was elevated levels serum of protein and albumin in the kidney of diclofenac treated rats.

Multiple factors, such as dose regulation based on renal function, hydration and avoidance of nephrotoxic agents, have been suggested to prevent or improve drug-induced nephrotoxicity [12] [37]. Nevertheless, drug induced toxicity remains a major problem for health care specialists. Therefore, outcome of impressive approaches to understand the mechanisms of action of drugs and potential injurious chemicals can help to reduce renal injuries.

Several lines of evidence have shown that exposure to drugs can result in a number of side effects that can lead to various disease states including kidney diseases. In the current study, we evaluated kidney toxicity of diclofenac administered orally to rats for three days. The results from this study showed that 
diclofenac induced kidney injury via oxidative damage in rats. This was evidenced by the perturbation of the kidney antioxidant defence system.

Enzymatic antioxidants such as SOD and CAT inactivate superoxide anion and peroxide radicals by transforming them into water and oxygen [38]. These two enzymes serve as important line of defence against oxidative stress. Our results indicated decrease in the activities of SOD and CAT in the kidney of rats administered with diclofenac. This is in accordance with the report of [39] [40]. GPx an enzymatic antioxidant that aids the GSH in the scavenging of hydroxyl radical and singlet oxygen directly as well as in the detoxification of hydrogen peroxides and lipid hydroperoxides.GST functions in cell survival and protection against oxidative stress [41]. GST is concerned in the conjugation of electrophilic oxidants with GSH to form water soluble compound products that are readily excreted from the system [22] [42]. The depletion of these vital enzymes revealed a serious damage to the kidney through generation of ROS.

GSH depleted in rats administered with diclofenac. GSH is considered as a free radical scavenger that acts as a non-enzymatic antioxidant by directly interacting with ROS via its thiol group. It is a co-substrate of GST in the conjugation of electrophilic species, and also as a substrate for GPx [43] [44]. Thus, the decrease in the level of GSH in the kidney of rats after administration of diclofenac, might be due to its conjugation with diclofenac to form diclofenac-SG adduct and/or its rapid utilization by the glutathione-dependent enzymes or its overutilization by the cell possibly to combat ROS generation in the piroxicam-treated rats.

It is generally believed that the toxicity of diclofenac is strongly linked with oxidative stress leading to lipid peroxidation and damage to the cellular macromolecules [2] [10]. In this study, diclofenac increased the kidney MDA and $\mathrm{H}_{2} \mathrm{O}_{2}$ levels. The MDA, being a product of lipid peroxidation, is produced in response to the oxidative deterioration of polyunsaturated fatty acids (PUFAs) in kidney membranes. In this situation, lipid peroxides are produced in the membranes of the kidney tissues. $\mathrm{H}_{2} \mathrm{O}_{2}$ is a normal product of aerobic metabolism in animals; however, its level is enhanced during conditions of intracellular build-up of reactive oxygen species (ROS) concentration [45]. The result of this study agreed with the report of [40].

\section{Conclusion}

In conclusion, this research work affirmed that diclofenac induced kidney damage in experimental animals by exploring the cellular mechanisms of its action that leads to oxidative damage apart from the routine test biomarkers.

\section{Conflicts of Interest}

The authors declared no competing interests.

\section{References}

[1] Sembuling, K. and Sembuling, P. (2012) Essential of Medical Physiology. 6th Edi- 
tion, New Jaypee Brothers Medical Publishers, Delhi, India.

[2] Ungprasert, P., Cheungpasitporn, W., Crowson, C.S. and Matteson, E.L. (2015) Individual Non-Steroidal Anti-Inflammatory Drugs and Risk of Acute Kidney Injury: A Systematic Review and Meta-Analysis of Observational Studies. European Journal International Medicine, 26, 285-291. https://doi.org/10.1016/j.ejim.2015.03.008

[3] Zhang, X., Donnan, P.T., Bell, S., et al. (2017) Non-Steroidal Anti-Inflammatory Drug Induced Acute Kidney Injury in the Community Dwelling General Population and People with Chronic Kidney Disease: Systematic Review and Meta-Analysis. BMC Nephrology, 18, 256. https://doi.org/10.1186/s12882-017-0673-8

[4] Walter Hörl, H. (2010) Nonsteroidal Anti-Inflammatory Drugs and the Kidney. Pharmaceuticals, 3, 2291-2321. https://doi.org/10.3390/ph3072291

[5] Dhanvijay, P., Arup Misra, K. and Sushil Varma, K. (2013) Diclofenac Induced Acute Renal Failure in Adecompensated Elderly Patient. Journal of Pharmacology and Pharmacothereutics, 4, 155-157. https://doi.org/10.4103/0976-500X.110916

[6] Bosch-Marcé, M., Clària, J., Titos, E., Masferrer, J.L., Altuna, R., Poo, J.L., et al. (1999) Selective Inhibition of Cyclooxygenase 2 Spares Renal Function and Prostaglandin Synthesis in Cirrhotic Rats with Ascites. Gastroenterology, 116, 1167-1175. https://doi.org/10.1016/S0016-5085(99)70020-X

[7] Blair, H.A. and Plosker, G.L. (2015) Diclofenac Sodium Injection (Akis, Dicloin): A Review of Its Use in the Management of Pain. Clinical and Drug Investigation, 35, 397-404. https://doi.org/10.1007/s40261-015-0294-6

[8] Hoy, S.M. (2016) Diclofenac Sodium Bolus Injection (Dyloject ${ }^{\mathrm{TM}}$ ): A Review in Acute Pain Management. Drugs, 76, 1213-1220. https://doi.org/10.1007/s40265-016-0619-7

[9] Hossain, M.K., Khatun, A., Rahman, M., Akter, M.N., Chowdhury, S.A. and Alam, S.M. (2016) Characterization of the Effect of Drug-Drug Interaction on Protein Binding in Concurrent Administration of Sulfamethoxazol and Diclofenac Sodium Using Bovine Serum Albumin. Advanced Pharmacology Bulletin, 6, 589.

[10] Lonappan, L., Brar, S.K., Das, R.K., Verma, M. and Surampalli, R.Y. (2016) Diclofenac and Its Transformation Products: Environmental Occurrence and Toxicity-A Review. Environmental International, 96, 127-138. https://doi.org/10.1016/j.envint.2016.09.014

[11] Ahmed, A.Y., Gad, A.M. and El-Raouf, M.A.O. (2017) Curcumin Ameliorates Diclofenac Sodium-Induced Nephrotoxicity in Male Albino Rats. Journal of Biochemistry and Molecular Toxicology, 31, e21951. https://doi.org/10.1002/jbt.21951

[12] Nouri, A. and Heidarian, E. (2019) Nephroprotective Effect of Silymarin against Diclofenac-Induced Renal Damage and Oxidative Stress in Male Rats. Journal of Herbmed Pharmacology, 8, 146-152. https://doi.org/10.15171/jhp.2019.23

[13] Public Health Service (1996) Policy on Humane Care and Use of Laboratory Animals. US Department of Health and Human Services, Washington DC.

[14] Fawcett, J.K. and Scott, J.E. (1960) A Rapid and Precise Method for the Determination of Urea. Journal of Clinical Pathology, 13, 156-159. https://doi.org/10.1136/jcp.13.2.156

[15] Henry, R.J. (1974) Clinical Chemistry, Principles and Techniques. 2nd Edition, Harper and Row, Hagerstown, MD.

[16] Tietz., N. (1995) Clincal Guide to Laboratory Tests. 3rd Edition, WB. Saunders, Philadelphia, PA, 268-273.

[17] Fossati, P., Prencipe, L. and Berti, G. (1980) Use of 3,5-Dichloro-2-Hydroxybenze- 
nesulfonic Acid/4-Aminophenazone Chromogenic System in Direct Enzymic Assay of Uric Acid in Serum and Urine. Clinical Chemistry, 26, 227-231. https://doi.org/10.1287/mnsc.26.2.227

[18] Webster, D. (1997) Biochemical Parameters and Its Assay. Clinical Chemistry, 23, 663-665.

[19] George Goodland, A.J. and Catherine Clark, M. (1982) Alteration in Hepatic 5'-Nucleotidase in Tumor Bearing Rat. Enzyme, 27, 119-123. https://doi.org/10.1159/000459035

[20] Misra, H.P. and Fridovich, I. (1972) The Role of Superoxide Anion in the Autoxidation of Epinephrine and a Simple Assay for Superoxide Dismutase. The Journal of Biological Chemistry, 247, 3170-3175

[21] Aebi, H. (1984) Catalase in Vitro. Methods Enzymology, 105, 121-126. https://doi.org/10.1016/S0076-6879(84)05016-3

[22] Rotruck, J.T., Pope, A.L., Ganther, H.E., Swanson, A.B. and Hoekstra, W.G. (1973) Selenium: Biochemical Role as a Component of Glutathione Peroxidase. Science, 179, 588-590. https://doi.org/10.1126/science.179.4073.588

[23] Habig, W.H., Pabst, M.J. and Jakoby, W.B. (1974) Glutathione S-Transferase; The First Enzymatic Step Inmercapturic Acid Formation. Journal Biological Chemistry, 249, 7130-7139.

[24] Jollow, D.J., Mitchell, J.R., Zampaglione, N. and Gillette, J.R. (1974) Bromobenzene Induced Liver Necrosis: Protective Role of Glutathione and Evidence for 3,4-Bromobenzene Oxide as the Hepatotoxic Metabolite. Pharmacology, 11, 151-169. https://doi.org/10.1159/000136485

[25] Buege, J.A. and Aust, S.D. (1978) Microsomal Lipid Peroxidation. Method Enzymology, 30 302-310. https://doi.org/10.1016/S0076-6879(78)52032-6

[26] Wolff, S.P. (1994) Ferrous Ion Oxidation in Presence of Ferric Ion Indicator Xylenol Orange for Measurement of Hydroperoxides. Methods Enzymology, 233, 182-189. https://doi.org/10.1016/S0076-6879(94)33021-2

[27] Gornall, A.G., Bardawill, C.J. and David, M.M. (1949) Determination of Serum Proteins by Means of the Biuret Reaction. Journal of Biological Chemistry, 177, 751-766.

[28] Bancroft, J.D. and Gamble, M. (2008) Theory and Practice of Histology Techniques. 6th Edition, Churchill Livingstone Elsevier, London, 83-134.

[29] Naidoo, S. (2015) Drug and Kidney. South African Medical Journal, 105, 322. https://doi.org/10.7196/SAMJ.9537

[30] Adedara, I.A., Teberen, R., Ebokaiwe, A.P., Ehwerhemuepha, T. and Farombi, E.O. (2012) Induction of Oxidative Stress in Liver and Kidney of Rats Exposed to Nigerian Bonny Light Crude Oil. Environmental Toxicology, 27, 372-379. https://doi.org/10.1002/tox.20660

[31] Komhoff, M.A., Grone, H.J., Klein, T.H., Seyberth, H.W. and Nusing, R.M. (1997) Localization of Cyclooxygenase-1 and-2 in Adult and Fetal Human Kidney: Implication for Renal Function. American Journal of Physiology-Renal Physiology, 272, F460-F468. https://doi.org/10.1152/ajprenal.1997.272.4.F460

[32] Fattori, V., Sergio Borghi, M., Carla Guazelli, F.S., Andressa Giroldo, C., Crespigio, J., Allan Bussmann, J.C., Coelho-Silva, L., Natasha Ludwig, G., Tânia Mazzuco, G., Casagrande, R. and Waldiceu Verri Jr., A. (2017) Vinpocetine Reduces Diclofenac-Induced Acute Kidney Injury through Inhibition of Oxidative Stress, Apoptosis, Cytokine Production, and NF- $\kappa \mathrm{B}$ Activation in Mice. Pharmacological Re- 
search, 120, 10-22. https://doi.org/10.1016/j.phrs.2016.12.039

[33] Borghi, S.M., Fattori, V., Ruiz-Miyazawa, K.W., Bertozzi, M.M., Lourenco-Gonzalez, Y., Tatakihara, R.I., et al. (2018) Pyrrolidine Dithiocarbamate Inhibits Mouse Acute Kidney Injury Induced by Diclofenac by Targeting Oxidative Damage, Cytokines and NF- $\kappa$ B Activity. Life Science, 208, 221-231. https://doi.org/10.1016/j.lfs.2018.07.038

[34] Ali Nouri, E.H. (2019) Nephroprotective Effect of Silymarin against Diclofenac-Induced Renal Damage and Oxidative Stress in Male Rats. Journal of Herbmed Pharmacology, 8, 146-152. https://doi.org/10.15171/jhp.2019.23

[35] Finn, W. and Porter, G. (2003) Urinary Biomarkers and Nephrotoxicity. Clinical Nephrotoxins, 2nd Edition, Kluwer Academic Publishers, Philip Drive Norwell, MA, 621-655. https://doi.org/10.1007/1-4020-2586-6_33

[36] Tojo, A. and Kinugasa, S. (2012) Mechanisms of Glomerular Albumin Filtration and Tubular Reabsorption. International Journal of Nephrology, 2012, Article ID: 481520. https://doi.org/10.1155/2012/481520

[37] Al-Snafi, A.E. (2015) Therapeutic Properties of Medicinal Plants: A Review of Their Detoxification Capacity and Protective Effects (Part 1). Asian Journal of Pharmaceutical Science and Technology, 5, 257-270.

[38] Tremellen, K. (2008) Oxidative Stress and Male Infertility-A Clinical Perspective. Human Reproductive Update, 14, 243-258. https://doi.org/10.1093/humupd/dmn004

[39] Nouri, A., Heidarian, E. and Nikoukar, M. (2017) Effects of N-Acetyl Cysteine on Oxidative Stress and TNF- $\alpha$ Gene Expression in Diclofenac-Induced Hepatotoxicity in Rats. Toxicological Mechanism Methods, 27, 561-567. https://doi.org/10.1080/15376516.2017.1334732

[40] El-Maddawy, Z.K. and El-Ashmawy, I.M. (2013) Hepato-Renal and Hematological Effects of Diclofenac Sodium in Rats. Global Journal of Pharmacology, 7, 123-132.

[41] Calabrese, E.J. and Iavicoli, I.V. (2013) Calabrese, Hormesis: Its Impact on Medicine and Health. Human Experimental Toxicology, 32, 120-152. https://doi.org/10.1177/0960327112455069

[42] Masella, R., Di Benedetto, R., Varı, R., Filesi, C. and Giovannini, C. (2005) Novel Mechanisms of Natural Antioxidant Compounds in Biological Systems: Involvement of Glutathione and Glutathione Related Enzymes. Journal of Nutritional Biochemistry, 16, 577-586. https://doi.org/10.1016/j.jnutbio.2005.05.013

[43] Bauche, F., Fouchard, M.H. and Jegou, B. (1994) Antioxidant System in Rat Testicular Cells. FEBS Letter, 349, 392-396. https://doi.org/10.1016/0014-5793(94)00709-8

[44] Doreswamy Muralidhara, K. (2005) Genotoxic Consequences Associated with Oxidative Damage in Testis of Mice Subjected to Iron Intoxication. Toxicology, 206, 169-178. https://doi.org/10.1016/j.tox.2004.07.010

[45] Klaunig, J.E., Kamendulis, L.M. and. Hocevar, B.A. (2010) Oxidative Stress and Oxidative Damage in Carcinogenesis. Toxicological Pathology, 38, 96-109. https://doi.org/10.1177/0192623309356453 